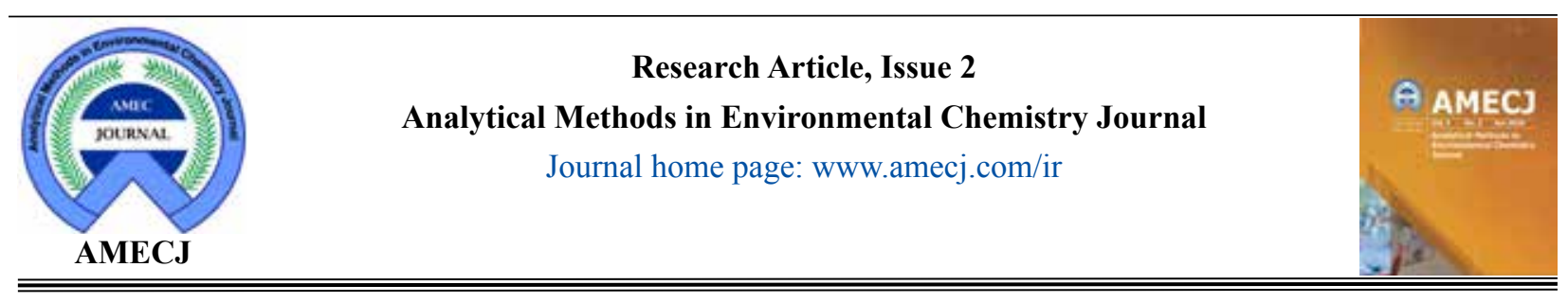

\title{
Facile synthesis of a modified HF-free MIL-101(Cr) nanoadsorbent for extraction nickel in water and wastewater samples
}

\author{
Saeed Fakhraie a,* and Ali Ebrahimi ${ }^{b}$
}

${ }^{a}$ Chemistry Department, Yasouj University, P.O. Box 74831-75918, Yasouj, Iran

${ }^{b}$ Occupational Health Engineering Department, School of Public Health, Qom University of Medical Sciences, Qom, Iran

\author{
A R T I C L E I N F O : \\ Received 16 Feb 2020 \\ Revised form 12 Apr 2020 \\ Accepted 8 May 2020 \\ Available online 28 Jun 2020 \\ Keywords: \\ MIL-101(Cr) nanoadsorbent, \\ Nickel, \\ Water and wastewaters, \\ Dispersive suspension micro solid phase \\ extraction, \\ Atom trap-flame atomic absorption \\ spectrometry
}

\begin{abstract}
A B S T R A C T
A novel sorbent based on MIL-101(Cr) nanoadsorbent as a MOF structure was used for nickel extraction from water and wastewater samples. In this study, $30 \mathrm{mg}$ of MIL-101(Cr) nanoadsorbent dispersed in $50 \mathrm{~mL}$ of water or wastewater samples, after sonication and adjusting $\mathrm{pH}=8.5$, the nickel ions was extracted by carboxyl groups of terephthalic acid $\left(\mathrm{MOF}-\left(\mathrm{C}_{6} \mathrm{H}_{4}(\mathrm{COO})^{2-} \ldots \mathrm{Ni}^{2+}\right)\right.$ by dispersive suspension-micro solid-phase extraction (DS- $\mu-\mathrm{SPE}$ ). The MOF was separated from liquid phase with filter membrane $(0.2$ $\mu \mathrm{m})$, eluted with $0.5 \mathrm{~mL}$ of nitric acid as back-extraction solution and finally, the nickel concentration in elution was determined by atom trap-flame atomic absorption spectrometry (AT-FAAS) after dilution with DW up to $1 \mathrm{~mL}$. The LOD, the linear range and preconcentration factor were achieved $1.5 \mu \mathrm{g} \mathrm{L}^{-1}, 5-160 \mu \mathrm{g} \mathrm{L}^{-1}$ and 49.7, respectively. The absorption capacity of MOF for nickel was obtained $136.8 \mathrm{mg}$ $\mathrm{g}^{-1}$. The results of procedure were validated by spiking of samples and ET-AAS analyzer.
\end{abstract}

\section{Introduction}

Nickel is the 28th element of Periodic table that found in abundance the earth's crust [1-4]. Pure nickel is a hard, silvery white, lustrous, malleable, ductile, shining metal with high electrical and thermal conductivity $[2,5]$. The soluble nickel salts and metallic nickel, nickel sulphides and nickel oxides are poorly water soluble [2]. Nickel as a heavy metal, nonessential great environmental concern because widely occurring in the environment from various natural sources including emissions from fossil fuel consumption and anthropogenic processes

\footnotetext{
${ }^{*}$ Corresponding Author: Saeed Fakhraie

Email: saeedfakhraie@yahoo.com

https://doi.org/10.24200/amecj.v3.i02.103
}

including modern technologies and production of products such as coins, jewelry, stainless steel, batteries, medical devices, plating and welding [69]. In 2008, nickel received the shameful name of the "Allergen of the Year" [8]. Humans are exposed to nickel in both occupational and Non-occupational forms. Occupational exposure to Nickel is primarily associated with workers in the producing and using of Nickel in industry sectors. Non-occupational sources of nickel exposure include is food, air and water. Human exposure to nickel occurs of inhalation, dermal contact, and gastrointestinal primary routes. Some specific aspects of nickel toxicities include Genotoxicity, Developmental toxicity, Neurotoxicity, Haematotoxicity, Immunotoxicity, Neurotoxicity 
and Carcinogenicity is $[2,4,5,8-11]$. The adverse health effects of nickel for humans depend on the route of exposure, water solubility of nickel compounds, dose, bodyweight, sensitivity and exposure periods [10]. Exposure to nickel causes irritation of the nose, vertigo, insomnia, sinuses and loss of sense of smell, headache, nausea, vomiting, chest pain, nonproductive cough, dyspnoea, cyanosis, abdominal pain, diarrhea, tachycardia, palpitations, sweating, visual disturbances, weakness, lassitude and shortness of breath, giddiness and it could also lead to asthma, bronchitis and other respiratory diseases, eventually causing lung cancer $[4,8,12]$. According to the Research on Cancer (IARC) and the U.S. Department of Health nickel sulfate, sulfides and oxides combinations of nickel are be classified in Group 1, (i.e. cancerogenic to humans) and metallic nickel in Group 2B, (i.e. Possibly carcinogenic to humans $[2,5,8,13]$. The Permissible Exposure Limit (PEL) by Occupational Safety and Health Administration (OSHA) for dust, fume and metal of nickel and Recommended Exposure Limit (REL) by National Institute of Occupational Safety and Health (NIOSH) for metal and soluble of nickel are 1 and $0.015 \mathrm{mg} \mathrm{m}^{3}$ respectively. In addition, World Health Organization (WHO) has proposed a guideline value of $20 \mu \mathrm{g} \mathrm{L}^{-1}$ for the maximum permissible concentration of nickel in drinking water $[14,15]$. A variety of methods such as cloud point extraction (CPE) [16-20], ionic liquid dispersive liquid-liquid micro extraction (IL-DLLME) [18,21], liquid-liquid extraction, cold induced aggregation microextraction (CIAME) [15], Solid phase extraction (SPE) [22-26], ligandless-ultrasound-assisted emulsification microextraction (USAEME) [27], coupled to various instrumental techniques like flame atomic absorption spectrometry (FAAS) [16,23,28,29,30-32] graphite furnace atomic absorption spectrometry (GFAAS) [33-34], ultrasonic nebulizer and inductively coupled plasma optic emission spectrometry (USN-ICPOES) [17], inductively coupled plasma atomic emission (ICP AES) [35], UV spectrometry [36], X-ray fluorescence spectrometry [37], inductively coupled plasma optic emission spectrometry (ICP-OES) [21], high performance liquid chromatography (HPLC) [38], inductively coupled plasma optic emission spectrometry (ICP-OES), have been developed for the for preconcentration and determination of nickel at low concentrations [39]. During the last decade, metal-organic frameworks (MOFs) have widely attracted international attention due to their high thermal stability, large surface area, and pore volume. Although a variety of MOFs has been developed, having their own particular properties, MIL (standing for materials of institute Lavoisier) structures have been more intriguing than other constituents owing to their extralarge cavities, high moisture stability, and lower production cost. For the first time, Ferey and his colleagues succeeded to synthesize nanoporous chromium terephthalate MIL-101(Cr) with a 3D structure by incorporating ter- ephthalic acid (benzene-1,4-dicarboxylic acid), chromium salt $\left(\mathrm{Cr}\left(\mathrm{NO}_{3}\right)_{3} \cdot 9 \mathrm{H}_{2} \mathrm{O}\right)$ and hydrofluoric acid (HF), as a modulator, in an aqueous medium [40]. In addition to the substantially large surface area and pore volume, they displayed that MIL$101(\mathrm{Cr})$ has an exclusive pore size distribution with two types of inner cages (29 $\AA$ and $34 \AA$ ) and windows $(12 * 12 \AA$ and $14.7 * 16 \AA)$. These promising features have unprecedentedly boosted the role of MIL-101(Cr) and its derivatives in the gas storage $\left(\mathrm{CO}_{2}\right.$ [43-44], $\mathrm{CH}_{4}$ [45-49] and $\mathrm{H}_{2}$ [50-53]), gas separation $\left(\mathrm{CO}_{2} / \mathrm{CH}_{4}\right.$ [54-56] and $\mathrm{CO}_{2} / \mathrm{N}_{2}$ [57-59]) and catalytic applications [60-63].

\section{Material and Methods}

\subsection{Instrumental}

The nickel concentration was determination by spectra GBC 906 double beam atom trap flame atomic absorption spectrophotometer with deuterium lamp as a background correction (AT-F AAS, GBC, Aus). The atom trap was installed on an air-acetylene burner. The operating software of 
AVANTA was utilized for collecting and storing data. A HCL of nickel adjusted at a current of 4.0 $\mathrm{mA}$ and a wavelength of $232.0 \mathrm{~nm}$ with a spectral bandwidth of $0.2 \mathrm{~nm}$. The working range for nickel was obtained $0.5-8 \mathrm{mg} \mathrm{L}^{-1}$. The $\mathrm{pH}$-meter (Metrohm 744 Switzerland), centrifuge (EBA, Germany) and ultrasonic bath (Kunshan) were used.

\subsection{Reagents and Materials}

In the synthesis procedure, chemicals including Chromium nitrate nonahydrate $\left(\mathrm{Cr}\left(\mathrm{NO}_{3}\right) 3.9 \mathrm{H}_{2} \mathrm{O}\right.$, 97\%), 1, 4-benzene dicarboxylic acid ( $\left.\mathrm{H}_{2} \mathrm{BDC}\right)$, Methanol (MeOH, Merck, 99.9\%), ethanol (EtOH, Merck, 99.9\%), N, N-dimethylformamide (DMF, Merck, 99.8\%) and Acetone were purchased from commercial vendors and utilized as received. (DI) water was employed as solvents. All reagents with analytical grade purchased from Merck (Darmstadt, Germany). Stock solutions of Ni(II) were prepared by dissolving powder amounts of $\mathrm{Ni}\left(\mathrm{NO}_{3}\right)_{2}$ in deionized water $(\mathrm{DW})$. The standard solutions were prepared daily by diluting with deionized water. Deionized water prepared from Milli-Q plus water from Millipore, USA. The $\mathrm{pH}$ of solutions was adjusted by ammonium chloride $\left(\mathrm{NH}_{3} / \mathrm{NH}_{4} \mathrm{Cl}\right)$ for $\mathrm{pH} 8-10$. All the laboratory glasses were cleaned by $10 \%(\mathrm{v} / \mathrm{v})$ nitric acid for $24 \mathrm{~h}$ and washed with DW 10 times.

\subsection{Preparation of MIL-101(Cr) nanoparticles}

In a typical procedure, $16 \mathrm{~g}$ of $\mathrm{Cr}\left(\mathrm{NO}_{3}\right)_{3} \cdot 9 \mathrm{H}_{2} \mathrm{O}$ and $6.56 \mathrm{~g}$ of terephthalic acid were separately added to deionized water $(200 \mathrm{~mL})$ and mixture was intensively stirred for $30 \mathrm{~min}$ with a magnetic stirrer. The resulting mixture was transferred to a stainless steel autoclave and heated at $220^{\circ} \mathrm{C}$ for 18 h. Upon heating, the mixture became as a soft green powder which was washed five times with boiling deionized water, three times with $\mathrm{MeOH}$ and three times with acetone in order to remove impurities and unreacted materials. In addition, to separate the remained terephthalic acid, the resulting solid was suspended in $50 \mathrm{~mL}$ of dimethylformamide and kept at $70^{\circ} \mathrm{C}$ overnight. After cooling, the sample was washed by pure ethanol for three times and the resulting powder was dried at $100{ }^{\circ} \mathrm{C}$ for $24 \mathrm{~h}$ to obtain the final product.

\subsection{Characterization}

To investigate the crystallinity and phase structure of the samples, powder X-ray diraction (PXRD) method was considered by using Philips PW-1730 instrument with $\mathrm{Cu}-\mathrm{K} \alpha$ radiation $(\lambda=1.5406 \AA)$. The scanning rate was $1 \mathrm{deg} / \mathrm{min}$ and operating power was $40 \mathrm{kV}$ and $40 \mathrm{~mA}$. To determine the functional groups, Fourier transform infrared spectroscopy (FT-IR) was performed using Bruker (VERTEX 70) spectrum from 400 to $4000 \mathrm{~cm}^{-1}$. Field Emission Scanning Electron Microscopy (FESEM) studies were carried out with a JEOL JEM 3010 instrument under $15 \mathrm{kV}$ voltage and 50 $\mathrm{kx}$ and $100 \mathrm{kx}$ magnifications. The specific surface area, total pore volume, average pore width and pore size distribution measurements was performed with a Micrometrics ASAP-2010 instrument by adsorption of nitrogen at $77 \mathrm{~K}$. Before analysis, the sample was degassed at $175^{\circ} \mathrm{C}$ and vacuum pressure for $2 \mathrm{~h}$ to remove moisture, solvents and other unwelcome molecules from pores.

\subsection{Analytical Procedure}

By DS- $\mu$-SPE procedure, the nickel ions were separated/preconcentrated from $50 \mathrm{~mL}$ of wastewater based on MIL-101(Cr) as MOF nanoadsorbent. First, the $\mathrm{pH}$ of wastewater samples and standard nickel solution containing 1$400 \mu \mathrm{g} \mathrm{L}^{-1}$ was adjusted up to 8.5 with phosphate or ammonium chloride buffer before adding $30 \mathrm{mg}$ of MIL-101(Cr). After shaking in ultrasonic bath for $5 \mathrm{~min}$ at room temperature $(50 \mathrm{kHz}, 100 \mathrm{~W})$, the nickel ions was extracted by carboxyl groups of MIL-101(Cr). Then the MIL-101 sorbent was separated from liquid phase with filter membrane $(0.2 \mu \mathrm{m})$ based on vacuum accessory and eluted with $0.5 \mathrm{~mL}$ of nitric acid as back-extraction solution. Finally, the nickel concentration in eluent was determined by atom trap-flame atomic absorption spectrometry (AT-FAAS) after dilution with DW up to $1 \mathrm{~mL}$ (Fig. 1). 


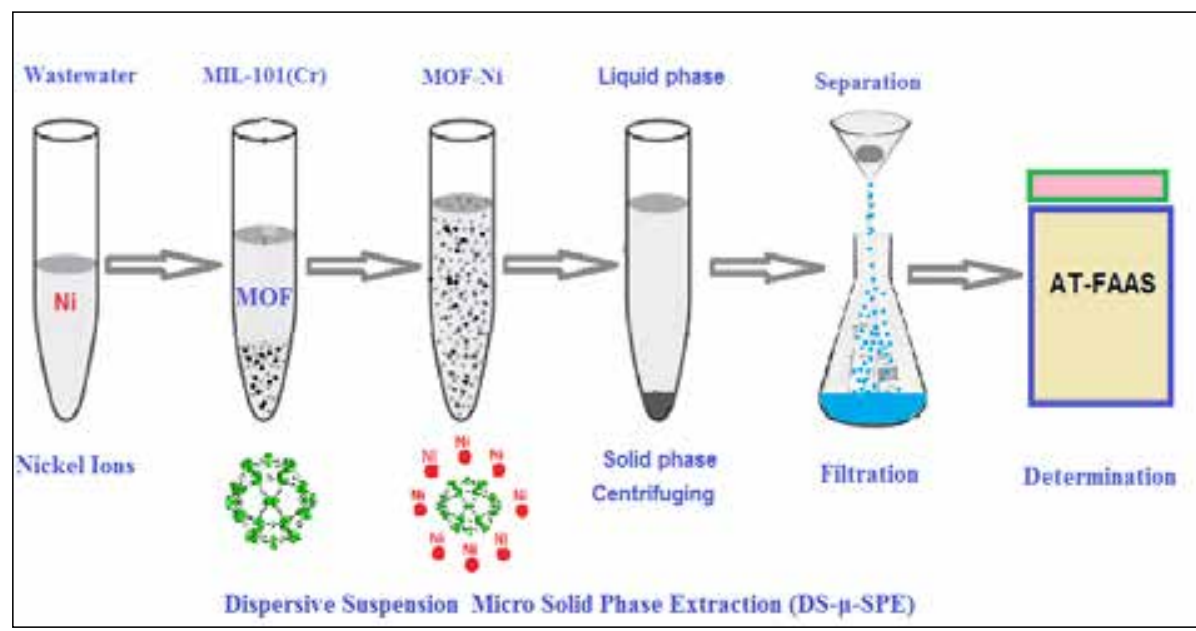

Fig.1. Nickel extraction based on MIL-101(Cr) from wastewater samples by DS- $\mu$ SPE procedure

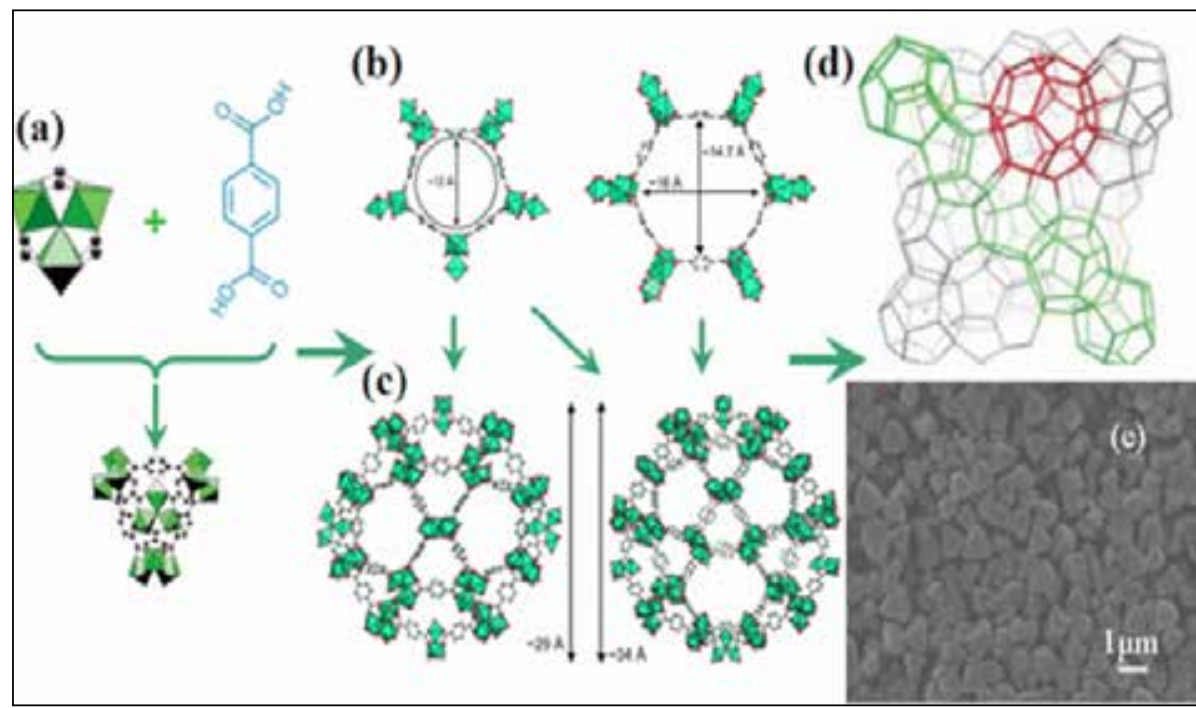

Fig.2. The robust framework of MIL-101 based on chromium (III) octahedral clusters
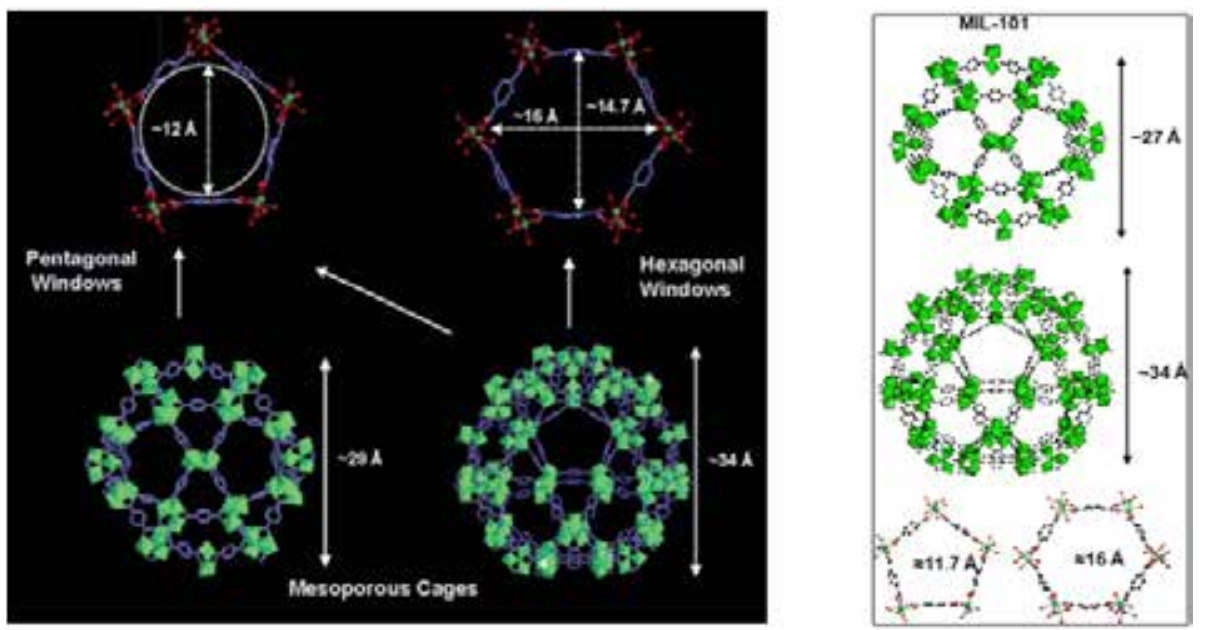

Fig.3. The structure of two types of mesoporous cages in MIL-101 with pentagonal forms 


\section{Results and discussion}

F'erey et al. prepared MIL-101 (MIL, Mat'erial Institut Lavoisier) with a chemical composition of $\left\{\mathrm{Cr}_{3} \mathrm{~F}\left(\mathrm{H}_{2} \mathrm{O}\right) 2 \mathrm{O}(\mathrm{BDC}) 3 \cdot \mathrm{nH}_{2} \mathrm{O}\right\}$ (n 25; 1, 4-benzenedicarboxylate (BDC) and superior physicochemical properties. The robust framework of MIL-101 was comprised of trimeric chromium (III) octahedral clusters interconnected by BDC molecules resulting in an augmented MTN zeotype structure (Fig. 2).

This structure was comprised of two types of mesoporous cages with diameters of $\sim 29$ and $34 \AA$ accessible through two types of microporous windows (the smaller cages have pentagonal windows with a free opening of $\sim 12 \AA$, while the larger cages possess both pentagonal and hexagonal windows with a $\sim 14.7 \AA$ by $16 \AA$ free aperture) (Fig. 3).

\subsection{Extraction Mechanism}

The material exhibits excellent stability against moisture and other chemicals, and the terminal water molecules in MIL-101 can be removed by heating in air or under vacuum at $423 \mathrm{~K}$, which generates two coordinatively unsaturated open metal sites (CUS) per trimeric Cr(III) octahedral cluster. In addition to its highly porous nature, MIL-101 has attracted considerable attention because functional modifications on MIL-101 can be achieved easily either directly using a functionalized ligand during the synthesis or indirectly via the diverse post-synthesis chemical treatment on the CUS or on the organic linkers. Among the MOFs known, MIL-101 is one of the most promising porous materials for future energy and environmental applications, surpassing MOF-5 or HKUST-1, owing to its superior physicochemical properties including high hydrothermal/chemical stability and desirable textural properties. Due to MIL-101 Structure nickel was physically and chemically extracted based on porous materials in MIL-101 nanostructure and covalence bonding by carboxyl groups of terephthalic acid (MOF- $\left(\mathrm{C}_{6} \mathrm{H}_{4}(\mathrm{COO})^{2-}\right.$ $\ldots . \mathrm{Ni}^{2+}$ ), respectively (Fig. 4).

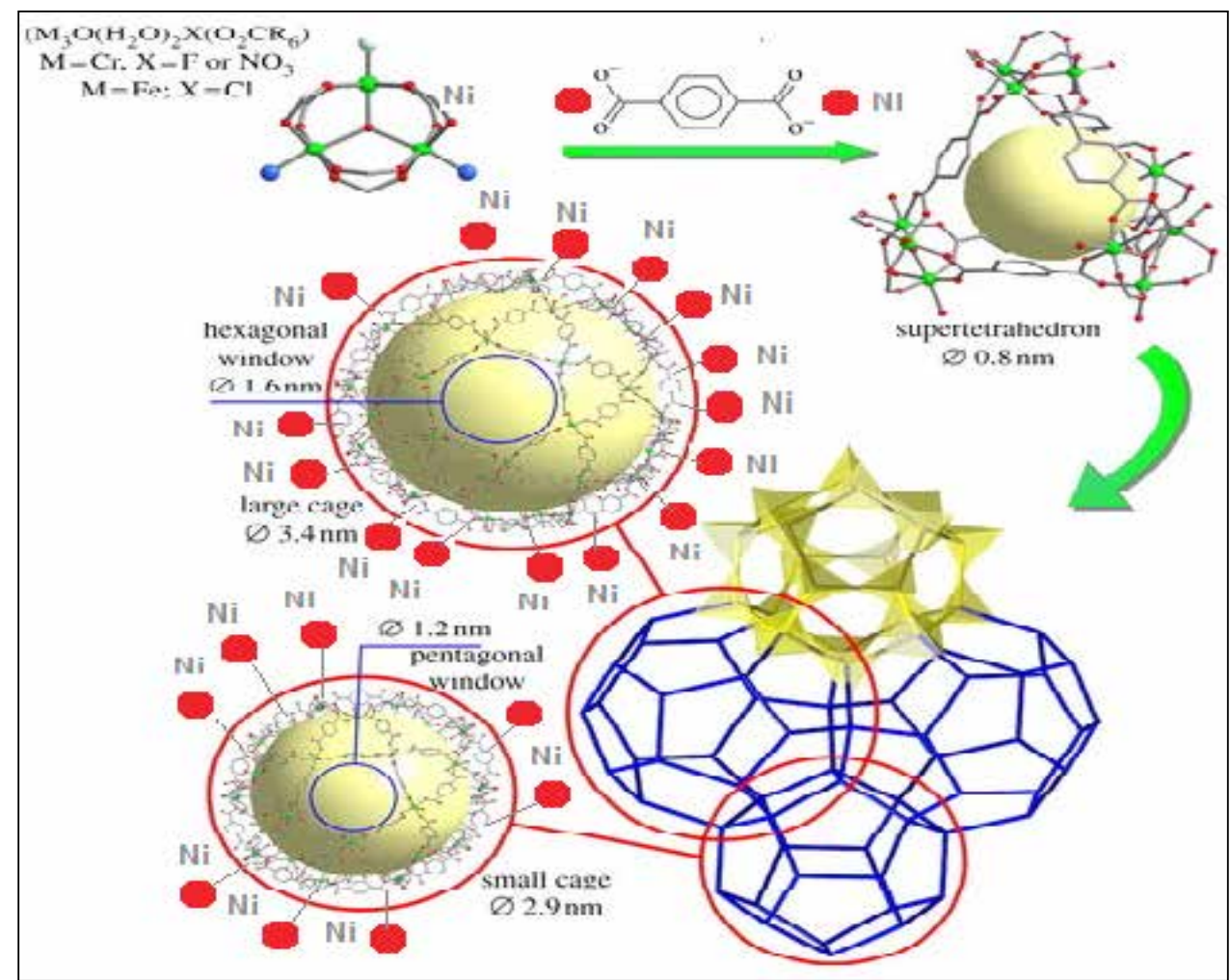

Fig. 4. The extraction mechanism of nickel by MIL-101 nanostructure 


\subsection{PXRD patterns}

PXRD pattern of the MIL-101(Cr) sample, prepared without modulators, is depicted in Figure 5. As it stated, MIL-101(Cr) possessed the most intensive peaks, as an indicator of the most crystallinity. The negligible peaks at around $2 \theta=17.4^{\circ}, 25.2^{\circ}$ or $27.9^{\circ}$ affirmed successful removal of unreacted $\mathrm{H}_{2} \mathrm{BDC}$ crystals from the sample framework [36]. Moreover, the main diraction peaks of MIL$101(\mathrm{Cr})\left(2 \theta \approx 5.25^{\circ}, 8.55^{\circ}, 9.15^{\circ}\right.$, and $\left.16.58^{\circ}\right)$ was thoroughly compatible with the MIL-101-HF-1, as a general reference for MIL-101(Cr).
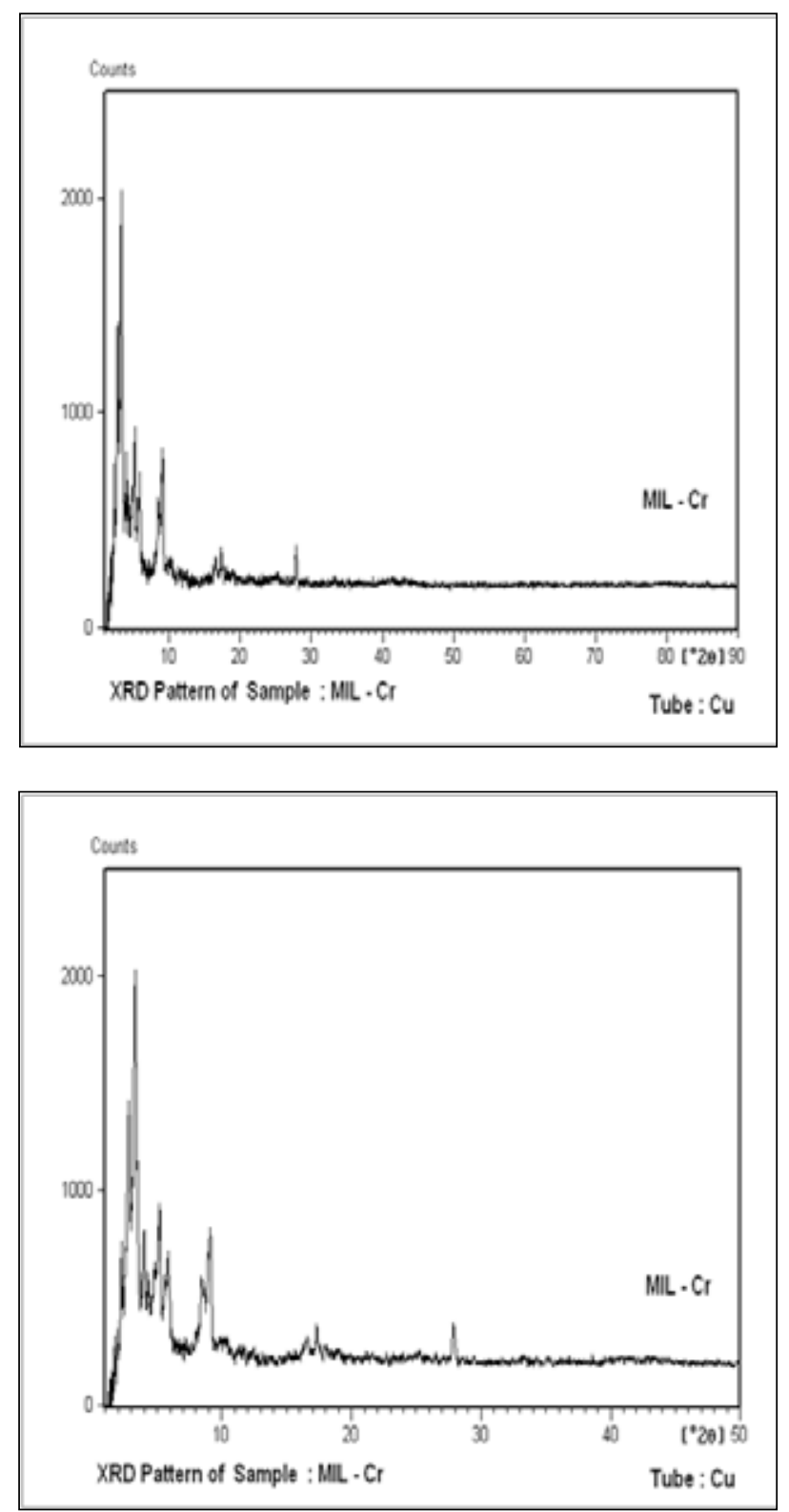

Fig. 5. The PXRD pattern of the MIL-101(Cr) sample

\subsection{FE-SEM}

The morphology of the prepared MIL-101(Cr) sample was characterized by field emission scanning electron microscope (FE-SEM) analysis. As it is seen in Figure 6, the image of MIL-101(Cr) shows highly crystalline octahedral morphology for this material which was compatible with the reported MIL-101(Cr) structures. In addition, there were no needleshaped crystals in the images representing the complete removal of $\mathrm{H}_{2} \mathrm{BDC}$ crystals by the postpurification process.
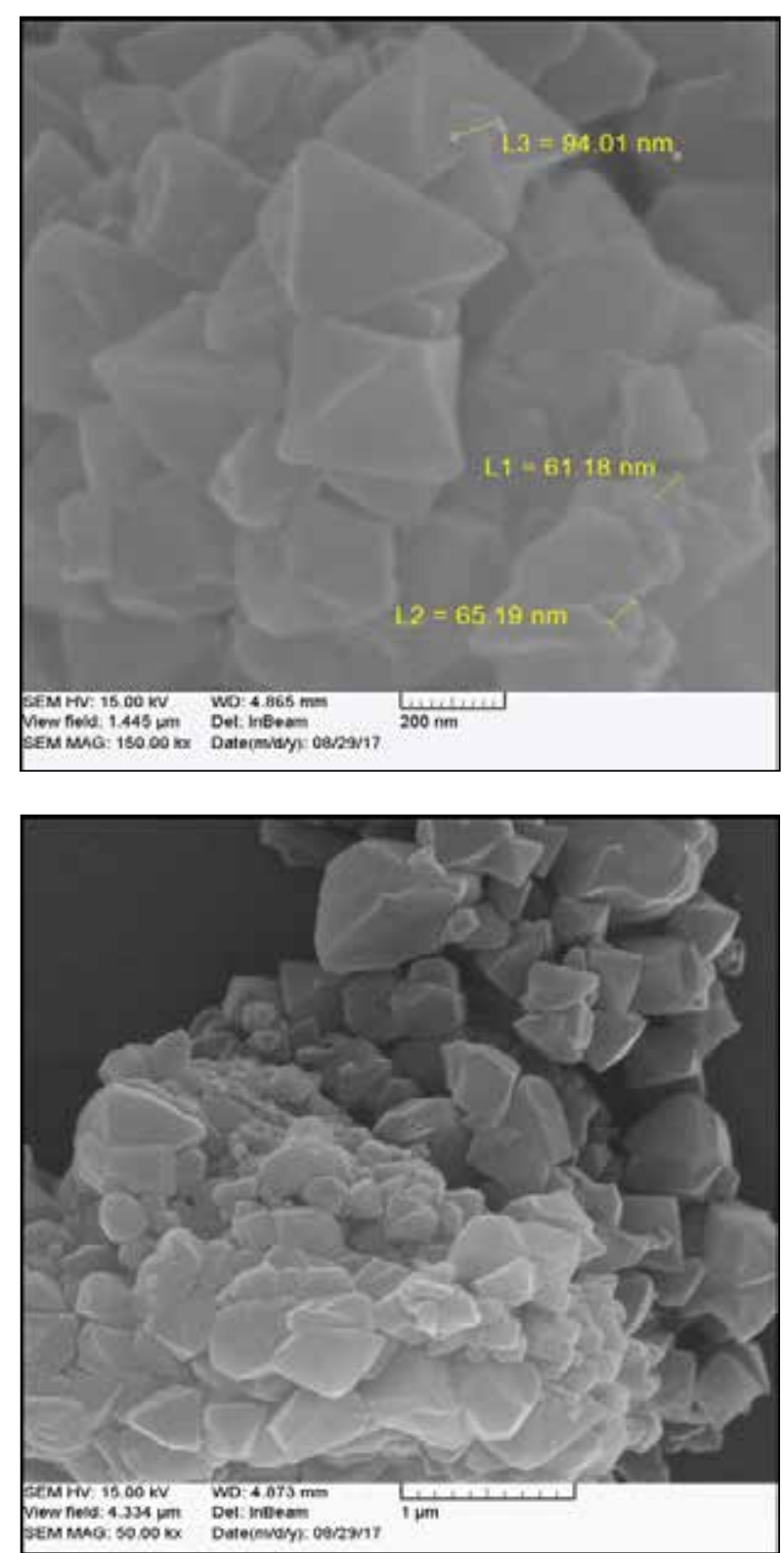

Fig. 6. The morphology of MIL-101(Cr) by field emission scanning electron microscope (FE-SEM) 


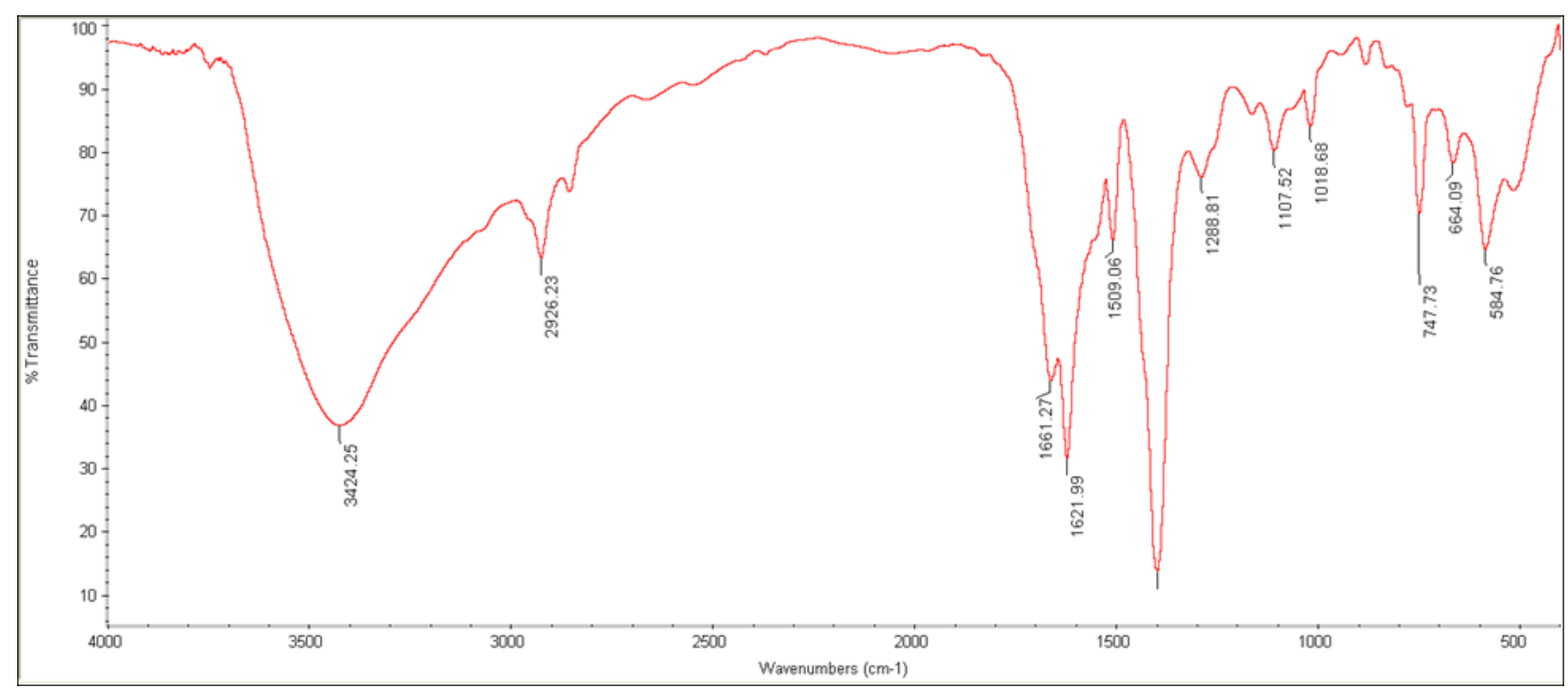

Fig. 7. FT-IR spectra of the synthesized MIL-101(Cr)

\subsection{FT-IR}

FT-IR spectra of the synthesized MIL-101(Cr) illustrated in Figure 7. In this spectrum the peak around of $570 \mathrm{~cm}^{-1}$ was assigned to the $\mathrm{Cr}-\mathrm{O}$ stretching vibration, reflecting the formation of MIL-101(Cr) structure. The peaks of between 600 and $1600 \mathrm{~cm}^{-1}$ were indicated to $\mathrm{H}_{2} \mathrm{BDC}$ and its aromatic rings. The bands at $750,884,1160 \mathrm{~cm}^{-1}$ were attributed to the $\mathrm{C}-\mathrm{H}$ bond in $\mathrm{CH}_{3}$ group and the peak observed at $1508 \mathrm{~cm}^{-1}$ indicates the $\mathrm{C}=\mathrm{C}$ stretching. A strong band at $1404 \mathrm{~cm}^{-1}$ is related to $\mathrm{O}-\mathrm{C}-\mathrm{O}$ symmetric vibrations and showing the dicarboxylate moiety in the sample. The typical bands located at 1625 and $3400 \mathrm{~cm}^{-1}$ confirmed the presence of hydroxyl groups or moisture in the sample. The FTIR results were in accordance to the previous reports FT-IR patterns which could be an evidence for the formation of MIL-101(Cr) structures (Fig. 7).

\subsection{Physical properties}

To determine physical properties of synthesized MIL-101(Cr) sample, the $\mathrm{N}_{2}$ sorption test at $77 \mathrm{~K}$ was carried out. The related $\mathrm{N}_{2}$ sorption isotherms along with the pore size distribution graphs are depicted in Figure 8. According to Figure 9-11, the $\mathrm{N}_{2}$ sorption isotherms exhibit the typical type I curve with sharp $\mathrm{N}_{2}$ adsorption at low partial pressures $(\mathrm{P} / \mathrm{P} 0<0.01)$ and a $\mathrm{H}_{2}$ hysteresis loop. In addition, the adsorbents have conical pores and crystals were composed of the microporous structure. The specific surface area and pore volume of MIL-101(Cr) were calculated and summarized in Table 1. The results indicated that MIL-101(Cr) possessed the BET surface area (2155 $\mathrm{m}^{2} \mathrm{~g}^{-1}$ ) and the Barrett-Joyner-Halenda (BJH) pore size distribution curve (b) derived from adsorption data of the isotherms indicates a main peak with average pore width of 2.1 for MIL-101(Cr). The result implies the microporous nature of samples and is in agreement with the results deduced from nitrogen adsorption-desorption isotherms and pore size distribution.

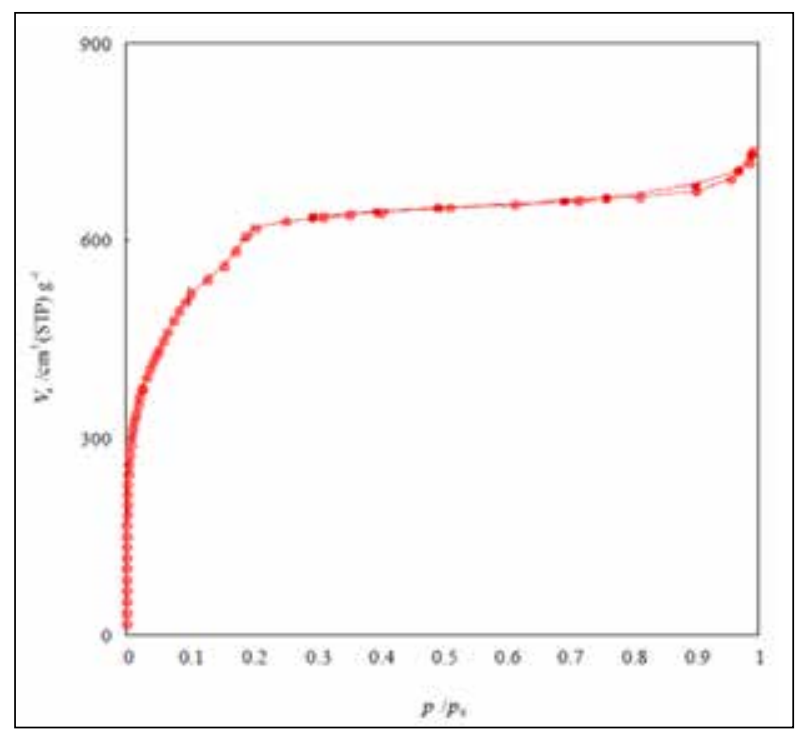

Fig. 8. Adsorption/desorption isotherm of $\mathrm{Cr}-\mathrm{MOF}$ adsorbent with adsorptive of $\mathrm{N}_{2}$ at $77 \mathrm{oK}$ 


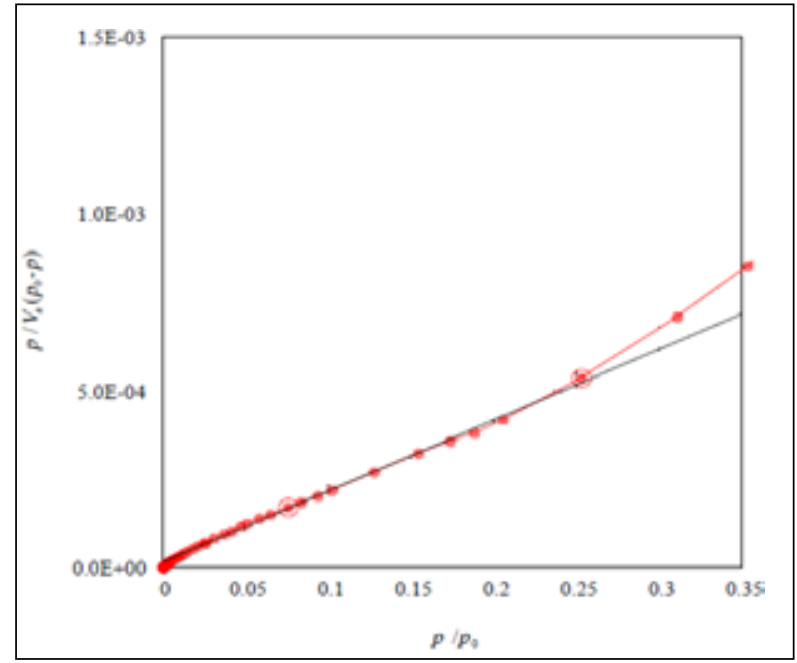

Fig. 9. BET plot of Cr-MOF adsorbent with adsorptive of $\mathrm{N}_{2}$ at $77^{\circ} \mathrm{K}$

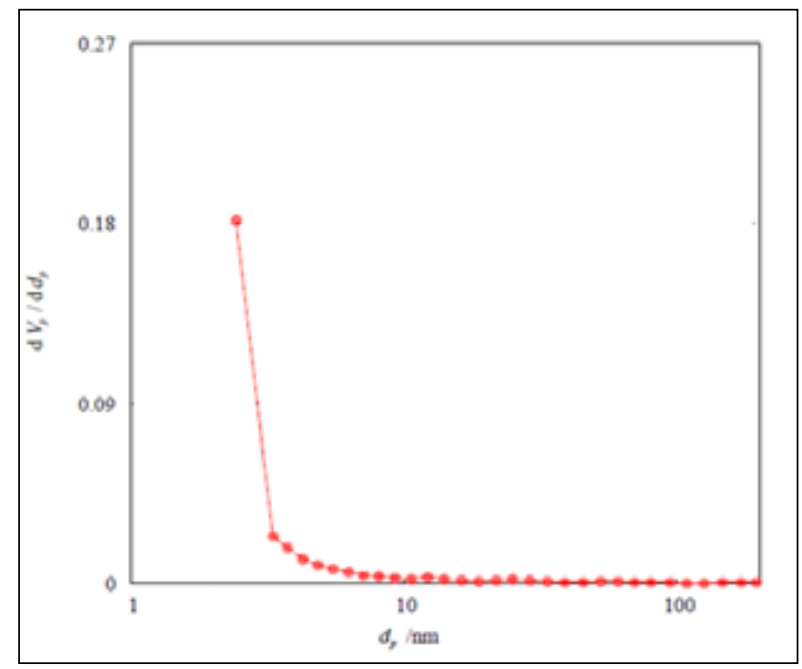

Fig. 10. BJH plot of Cr-MOF adsorbent for absorption branch at $77^{\circ} \mathrm{K}$

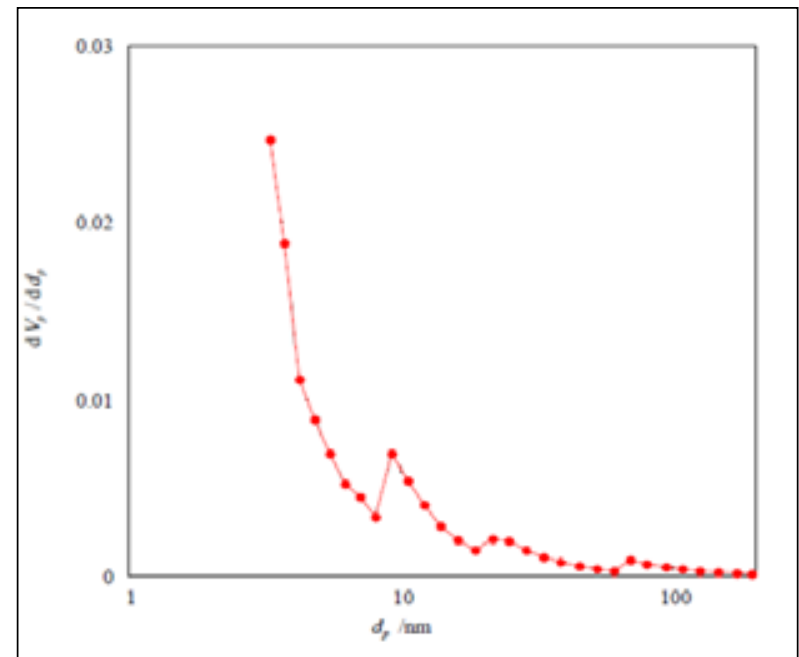

Fig. 11. BJH-plot of Cr-MOF adsorbent for desorption branch at $77^{\circ} \mathrm{k}$
Table 1. Physical properties of Cr-MOF (MIL-101(Cr))

\begin{tabular}{ccccc}
\multicolumn{5}{c}{ adsorbent } \\
Product & $\begin{array}{c}\text { BET } \\
\text { Surface } \\
\text { area } \\
\left(\mathrm{m}^{2} \mathrm{~g}^{-1}\right)\end{array}$ & $\begin{array}{c}\text { Average } \\
\text { pore } \\
\text { width } \\
(\mathrm{nm})\end{array}$ & $\begin{array}{c}\mathrm{Vm} \\
\left(\mathrm{cm}^{3} \mathrm{~g}^{-1}\right)\end{array}$ & $\begin{array}{c}\text { Total pore } \\
\text { volume } \\
\left(\mathrm{cm}^{3} \mathrm{~g}^{-1}\right)\end{array}$ \\
\hline MOF & 2155 & 2.1 & 495 & 1.13 \\
\hline
\end{tabular}

\subsection{Optimization}

The DS- $\mu$-SPE procedure based on Cr-MOF adsorbent was applied for speciation and preconcentration of nickel in water samples. For optimization many parameters such as amount of sorbent, volume of samples, shaking time, interference Ions and $\mathrm{pH}$ were optimized.

\subsubsection{Amount of sorbent}

For efficient extraction of nickel, the amount of MIL-101(Cr) nanoadsorbent was studied. For this purpose, the amounts of $5-50 \mathrm{mg}$ of MIL101(Cr) were used for nickel extraction by the DS- $\mu$-SPE method. The results showed, the high recoveries between $95-105 \%$ were obtained in wastewater samples with $28 \mathrm{mg}$ of MIL-101(Cr) for $\mathrm{Ni}$ extraction. Therefore, $30 \mathrm{mg}$ of MOF was used as optimum mass for $\mathrm{Ni}$ extraction at $\mathrm{pH}=8.5$ (Fig. 12).

\subsubsection{Volume of samples}

The sample volume for nickel extraction based on MOF was evaluated by DS- $\mu$-SPE method. In this study the vary volume of wastewater samples between $5-100 \mathrm{~mL}$ was studied and optimized for 5-160 $\mu \mathrm{g} \mathrm{L}^{-1}$ of nickel concentration. Based on results, the efficient extractions were achieved for $55 \mathrm{~mL}$ of wastewater samples. Therefore, $50 \mathrm{~mL}$ blood sample was selected as the optimal sample volume for further study (Fig. 13).

\subsubsection{The Shaking time}

The time of extraction depended on the sonication of MIL-101(Cr) nanoadsorbent in the wastewater samples, which was increased interaction between carboxyl group of MIL-101(Cr) with Ni(II) at 


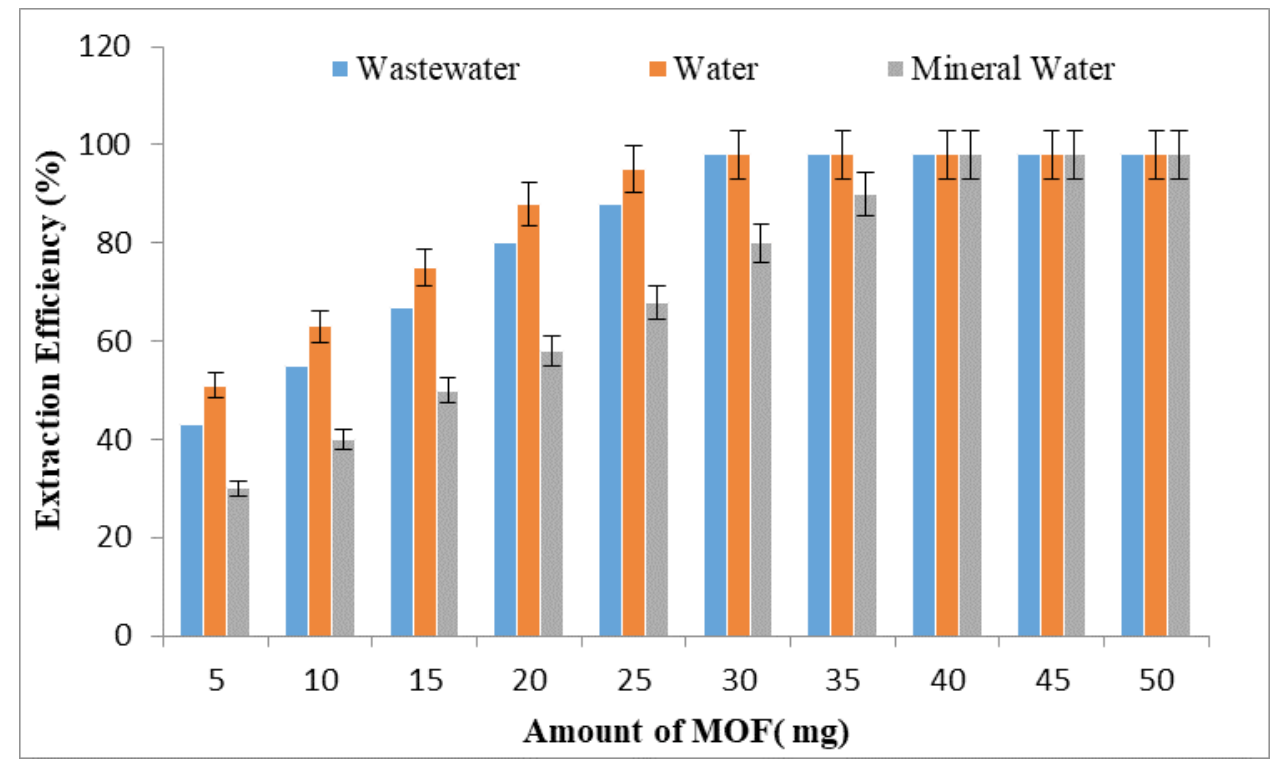

Fig. 12. The effect of MOF amount for Ni(II) extraction from water samples

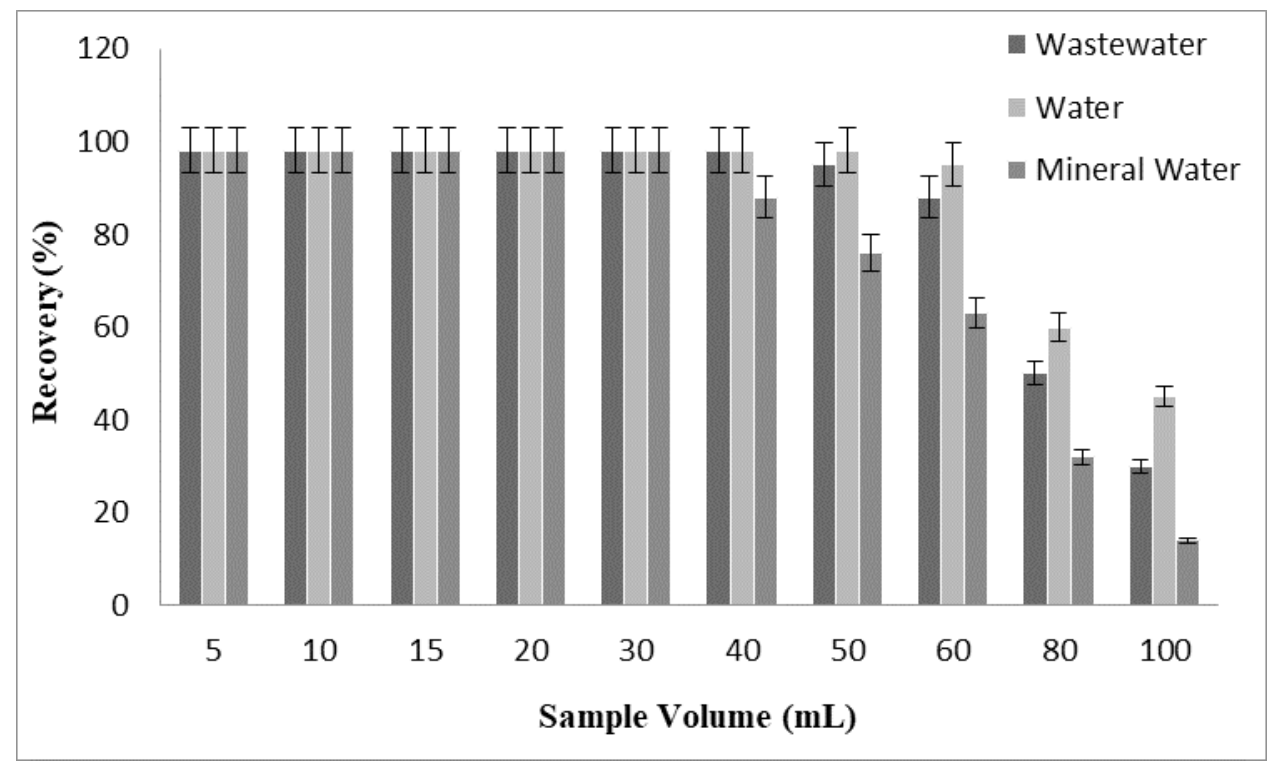

Fig.13. The effect of sample volume for Ni(II) extraction from water samples

$\mathrm{pH}=8.5$. By dispersion of the MIL-101(Cr), the mass-transference and extraction was performed. So, the effect of shaking time was studied for 1-20 min. By results, the sonication of $5.0 \mathrm{~min}$ had efficient extraction for $\mathrm{Ni}$ ions in wastewater samples for $30 \mathrm{mg}$ of sorbent. Therefore, 5.0 minute was used as the optimum shaking time by DS- $\mu$-SPE procedure.

\subsubsection{The pH effect}

The $\mathrm{pH}$ has main role for nickel extraction by MIL-101(Cr) nanoadsorbent. So, the effect of different $\mathrm{pH}$ (2-11) for extraction of $\mathrm{Ni}$ (II) in wastewater samples were investigated by DS- $\mu$ SPE procedure. The results demonstrated that the MIL-101(Cr) as MOF sorbent could be efficiently captured $\mathrm{Ni}$ (II) in $\mathrm{pH}$ of 8-8.5. Also, the recoveries 


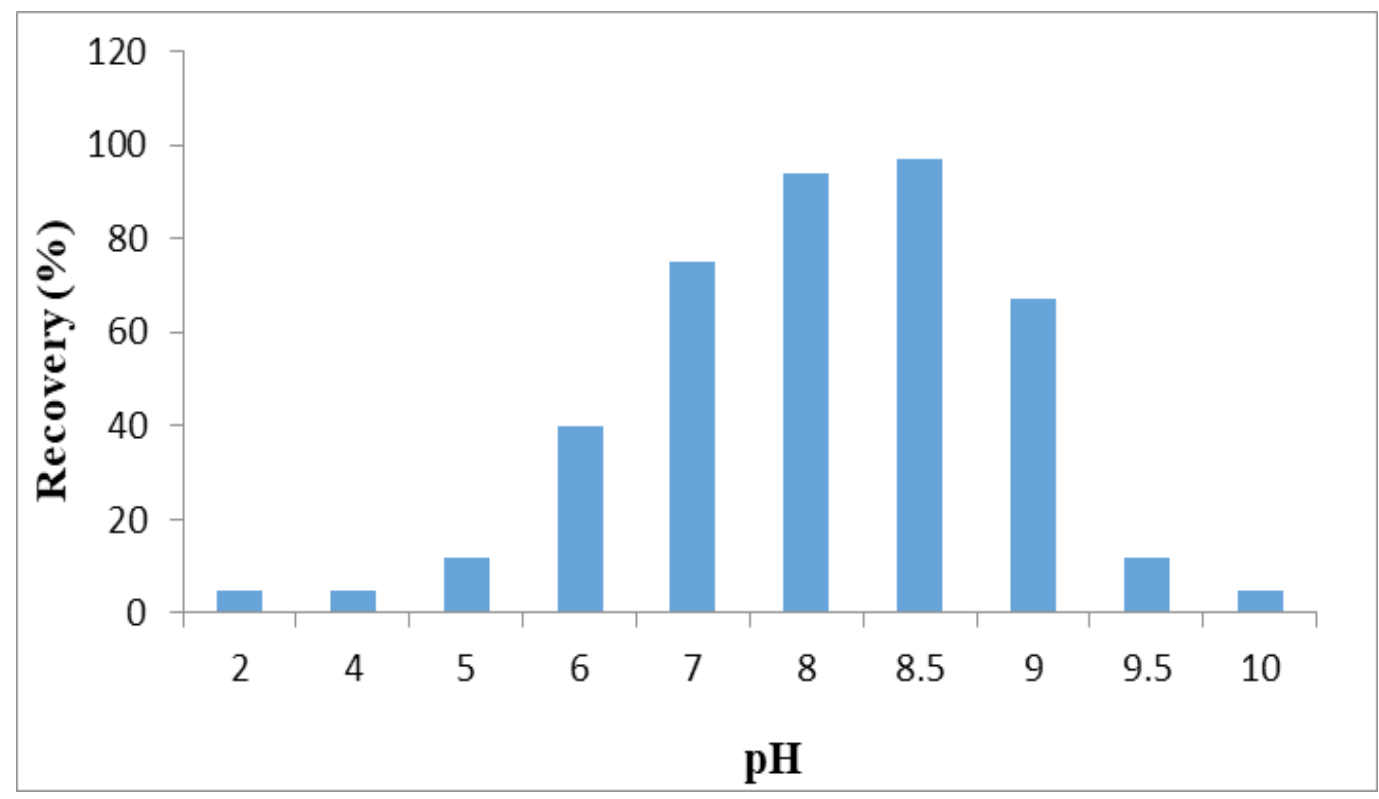

Fig. 14. The effect of $\mathrm{pH}$ for $\mathrm{Ni}(\mathrm{II})$ extraction based on MOF from water samples

for Ni (II) based on Cr-MOF were obtained more than $95 \%$ in $\mathrm{pH} 8.5$ and the decreased at lower and higher $\mathrm{pH}(7.5>\mathrm{pH}>9)$. So, $\mathrm{pH}=8.5$ was selected for further experiments (Fig. 14). The mechanism of nickel extraction depend on the coordination of covalent bond of sorbent $\left[\mathrm{Ni}^{2+} \rightarrow(\mathrm{COO})^{2-}\right]$ with the positively charged of nickel.

\subsubsection{Validation}

The validation of DS- $\mu$-SPE procedure based on MOF was obtained by spiking samples. The different concentration of nickel added to real samples as lower and upper ranges in wastewater and water samples. The results showed a good recovery between $95 \%-106 \%$ which was shown in Table 2. Also, the validation was confirmed with electrothermal atomic absorption spectrometry (ET-AAS) coupled with microwave digestion process (Table 3). Based on results in Tables 2 and 3 , the nickel ions were efficiently extracted by $\mathrm{Cr}-$ MOF adsorbent in optimized conditions.

Table 2. The validation of DS- $\mu$-SPE procedure based on MOF for nickel(II) extraction from water samples

\begin{tabular}{cccc}
\hline Samples & Added $\left(\mu \mathrm{g} \mathrm{L}^{-1}\right)$ & *Found $\left(\mu \mathrm{g} \mathrm{L}^{-1}\right)$ & Recovery $(\%)$ \\
\hline Water & ----- & $86.75 \pm 3.55$ & ---- \\
& 100 & $185.63 \pm 8.73$ & 98.8 \\
\hline Tab water & ----- & $6.22 \pm 0.34$ & ----- \\
& 5 & $11.53 \pm 0.48$ & 106.2 \\
\hline aWastewater & --------- & 95.9 \\
\hline Well water & 150 & $144.62 \pm 6.13$ & ----- \\
\end{tabular}

${ }^{*}$ Mean of three determinations \pm cconfidence interval $(\mathrm{P}=0.95, \mathrm{n}=8)$

${ }^{a}$ Wastewater samples diluted with DW (1:1) 
Table 3. Validation of methodology for nickel extraction from water samples by comparing to ET-AAS coupled with microwave digestion process

\begin{tabular}{cccccc}
\hline Samples & Added $\left(\mu \mathrm{g} \mathrm{L}^{-1}\right)$ & $\begin{array}{l}{ }^{*} \text { Found ETAAS } \\
\left(\mu \mathrm{g} \mathrm{L}^{-1}\right)\end{array}$ & $\begin{array}{l}{ }^{*} \text { Found AT-FAAS } \\
\left(\mu \mathrm{g} \mathrm{L}^{-1}\right)\end{array}$ & $\begin{array}{l}\text { Recovery } \\
\text { ETAAS }(\%)\end{array}$ & $\begin{array}{l}\text { Recovery AT- } \\
\text { FAAS }(\%)\end{array}$ \\
\hline Water 1 & ------ & $10.56 \pm 0.43$ & $10.18 \pm 0.52$ & ----- & ---- \\
& 10 & $20.31 \pm 0.86$ & $19.87 \pm 0.93$ & 97.5 & 96.9 \\
\hline Water 2 & ------ & $33.82 \pm 1.57$ & $31.95 \pm 1.63$ & ----- & ----- \\
& 30 & $62.98 \pm 2.78$ & $60.88 \pm 3.02$ & 97.2 & 96.4 \\
\hline Water 3 & ----- & $75.21 \pm 3.26$ & $73.93 \pm 3.39$ & ----- & ----- \\
& 50 & $125.73 \pm 6.03$ & $122.86 \pm 6.24$ & 101.1 & 97.8 \\
\hline Water 4 & ----- & $93.12 \pm 4.16$ & $94.27 \pm 4.43$ & ----- & ----- \\
& 100 & $191.62 \pm 8.94$ & $194.77 \pm 9.24$ & 98.5 & 100.5 \\
\hline
\end{tabular}

${ }^{*}$ Mean of three determinations \pm cconfidence interval $(\mathrm{P}=0.95, \mathrm{n}=8)$

Water1: Darband River,

Water 2: Hesarak River

Water 3: DarAbad River

Water 4: Zaferaniyeh and Velenjak River

\subsubsection{Discussions}

For metal determination with the DS- $\mu$-SPE procedure based on Cr-MOF adsorbent, the effect of the main parameters, such as amount of sorbent, volume of samples, shaking time, interference Ions and $\mathrm{pH}$ were optimized thoroughly. Results this study revealed that MIL-101(Cr) nanoadsorbent was used as a novel sorbent for dispersive suspension micro solid phase extraction (DS- $\mu$ SPE) nickel from environmental waters. In in study highly crystalline octahedral morphology of MIL101(Cr) sample as reported MIL-101(Cr) structures in other studies was characterized by field emission scanning electron microscope (FE-SEM) analysis $[64,65]$. FT-IR characterization was conducted to detect the identity of the MIL-101(Cr) functional groups that the FT-IR results were in accordance to the previous reports $[59,64-66]$. In this study, optimum mass of $\mathrm{MOF}, \mathrm{pH}$ and time for $\mathrm{Ni}$ extraction $30 \mathrm{mg}, 7.5$ and 5 minute at $\mathrm{pH}: 7.5,30$ respectively were obtained in wastewater samples so that Behbahani, M., et al. this parameters for Modification of magnetized MCM-41 by pyridine groups for ultrasonic-assisted dispersive microsolid-phase extraction of nickel ions $24 \mathrm{mg}, 7.5$ and 8 minute has been reported [67]. Based on results, under optimized conditions detection limit, the linear range were achieved of $1.5 \mu \mathrm{g} \mathrm{L}^{-1}, 5-160 \mu \mathrm{g}$ $\mathrm{L}^{-1}$. In study safavi et al. linear range for 2-aminocyclopentene-1-dithiocarboxylicacid absorbent and Cloud point extraction method linear in the range of 20-500 $\mu \mathrm{g} \mathrm{L}^{-1}$ Obtained [22]. The findings of this study showed that MIL-101(Cr) as a valid procedure for extraction nickel in water samples can be used.

\section{Conclusions}

The MIL-101(Cr) as a MOF nanoadsorbent was synthesized and used for nickel extraction from water samples by DS- $\mu$-SPE procedure. After extraction nickel ions with MOF adsorbent at $\mathrm{pH}=8.5$, it was back-extracted from adsorbent and finally, the concentration was determined by AT-FAAS. The low LOD of $1.5 \mu \mathrm{g} \mathrm{L}^{-1}$ and the favorite linear range 5-160 $\mu \mathrm{g} \mathrm{L}^{-1}$ was achieved. The high absorption capacity of $136.8 \mathrm{mg} \mathrm{g}^{-1}$ was obtained by MIL-101(Cr). The efficient, simple and fast extraction was achieved in low time by DS- $\mu$-SPE procedure. The MIL-101(Cr) as solidphase had high recovery more than $97 \%$ for $\mathrm{Ni}(\mathrm{II})$ extraction from waters without any chelating agents. Therefore, extraction of nickel based on 
MIL-101(Cr) can be used as efficient procedure for determination and separation of $\mathrm{Ni}(\mathrm{II})$ in water samples by AT-FAAS

\section{Acknowledgements}

The authors wish to thank Qom University of Medical Sciences, Qom, Iran, Iranian Petroleum Industry Health Research Institute (IPIHRI), and the Iranian Research Institute of Petroleum Industry (RIPI) for supporting of this work.

\section{References}

[1] E. Nieboer, J.O. Nriagu, Nickel and human health, International Conference on nickel metabolism and toxicology, Espoo, Finland. Wiley, 1992.

[2] K.K. Das, S.N. Das, S. A. Dhundasi, Nickel: molecular diversity, application, essentiality and toxicity in human health, Biometals: molecular structures, binding properties and applications, Nova Sci. Publishers, (2010) 3358.

[3] A. Arita, M. Costa, Epigenetics in metal carcinogenesis: nickel, arsenic, chromium and cadmium, Metallomics, 3 (2009) 222-228.

[4] K.S. Cameron, B. Virginia, B.T. Paul, Exploring the molecular mechanisms of nickel-induced genotoxicity and carcinogenicity: a literature review, Rev. Environ. Health, 2 (2011) 81-92.

[5] K.K. Das, S.N. Das, S. A. Dhundasi, Nickel, its adverse health effects \& oxidative stress, Indian J. Med. Res., 4 (2008) 412.

[6] A. Arita, M. Costa, Epigenetics in metal carcinogenesis: nickel, arsenic, chromium and cadmium, Metallomics, 3 (2009) 222-228.

[7] P.C. Nagajyoti, K.D. Lee, T.V.M. Sreekanth. Heavy metals, occurrence and toxicity for plants: a review, Environ. Chem. lett., 3 (2010) 199-216.

[8] A. Duda-Chodak, U. Blaszczyk, The impact of nickel on human health, J. Elem., 4 (2008) 685693.

[9] S. Buxton, E. Garman, K.E. Heim, T. LyonsDarden, C. E. Schlekat, M. D. Taylor, A.R. Oller, Concise review of nickel human health toxicology and ecotoxicology, Inorganics, 7 (2019) 89.

[10] N. Alam, S.J. Corbett, H.C. Ptolemy, Environmental health risk assessment of nickel contamination of drinking water in a country town in NSW, New South Wales Public Health bull., 10 (2008) 170-173.

[11] M.G. Permenter, J.A. Lewis, D.A. Jackson, Exposure to nickel, chromium, or cadmium causes distinct changes in the gene expression patterns of a rat liver derived cell line, PLOS one, 11 (2011) e27730.

[12] F. Akbal, S. Camc1, Copper, chromium and nickel removal from metal plating wastewater by electrocoagulation, Desalination, 3 (2011) 214-222.

[13] K. Bhupander, D.P. Mukherjee, Assessment of human health risk for arsenic, copper, nickel, mercury and zinc in fish collected from tropical wetlands in India, Adv. Life Sci. Technol., 2 (2011) 13-24.

[14] NIOSH Manual of analytical methods (NMAM, 5 Edition), U.S. department of health and human services, 2015.

[15] H. Abdolmohammad-Zadeh, E. Ebrahimzadeh. Ligandless cloud point extraction for trace nickel determination in water samples by flame atomic absorption spectrometry, J. Brazilian Chem. Soc., 3 (2011) 517-524.

[16] C.A. Şahin, M. Efeçınar, N. Şatıroğlu. Combination of cloud point extraction and flame atomic absorption spectrometry for preconcentration and determination of nickel and manganese ions in water and food samples, J. Hazard. Mater., 3 (2010) 672-677.

[17] A. Safavi, H. Abdollahi, M.R. Hormozi Nezhad, R. Kamali, Cloud point extraction, preconcentration and simultaneous spectrophotometric determination of nickel and cobalt in water samples, Spectrochim. Acta Part A: Mol. Biomol. Spec., 12 (2004) 2897-2901.

[18] J. Chen, K.C. Teo, Determination of cobalt and nickel in water samples by flame atomic absorption spectrometry after cloud point 
extraction, Anal. Chim. Acta, 2 (2001) 325-330.

[19] J.L. Manzoori, G. Karim-Nezhad, Development of a cloud point extraction and preconcentration method for $\mathrm{Cd}$ and $\mathrm{Ni}$ prior to flame atomic absorption spectrometric determination, Anal. Chim. Acta, 2 (2004) 173-177.

[20] C. Fan, Q. Pan, Q. Li, L. Wang, Cloud pointTiO 2/sepiolite composites extraction for simultaneous preconcentration and determination of nickel in green tea and coconut water, J. Iran. Chem. Soc., 2 (2016) 331-337.

[21] S.M.N. Moalla, A.S. Amin. An ionic liquid-based microextraction method for highly selective and sensitive trace determination of nickel in environmental and biological samples, Anal. Method., 24 (2015) 10229-10237.

[22] A. Moghimi, M.J. Poursharifi, Perconcentration of $\mathrm{Ni}$ (II) from sample water by modified nano fiber, Oriental J. Chem., 1 (2012) 353.

[23] S.Z. Mohammadi, D. Afzali, Y.M. Baghelani. Flame atomic absorption spectrometry determination of trace amounts of nickel ions in water samples after ligandless ultrasoundassisted emulsification microextraction, Anal. Sci., 9 (2010) 973-977.

[24] V.A. Lemos, G.S. Do Nascimento, L.S. Nunes, A new functionalized resin for preconcentration and determination of cadmium, cobalt, and nickel in sediment samples, Water, Air, Soil Pollut., 2 (2015) 2.

[25] H. Shirkhanloo, M. Falahnejad, H. Zavvar Mousavi, Mesoporous silica nanoparticles as an adsorbent for preconcentration and determination of trace amount of nickel in environmental samples by atom trap flame atomic absorption spectrometry, J. Appl. Spec., 6 (2016) 1072-1077.

[26] H. Sereshti, V. Khojeh, M. Karimi, S. Samadi, Ligandless-ultrasound-assisted emulsificationmicroextraction combined with inductively coupled plasma-optical emission spectrometry for simultaneous determination of heavy metals in water samples, Anal. Method., 1 (2012) 236-241.

[27] V.A. Lemos, V.J. Ferreira, J.A. Barreto,
L.A. Meira, Development of a method using ultrasound-assisted emulsification microextraction for the determination of nickel in water samples, Water, Air, Soil Pollut., 5 (2015) 141.

[28] M. Karimi, S. Dadfarnia, A.M.H. Shabani, Application of deep eutectic solvent modified cotton as a sorbent for online solid-phase extraction and determination of trace amounts of copper and nickel in water and biological samples, Biol. Trace Elem. Res., 1 (2017) 207215.

[29] M.R. Jamali, A. Madadjo, R. Rahnama. Determination of nickel using cold-induced aggregation microextraction based on ionic liquid followed by flame atomic absorption spectrometry, J. Anal. Chem., 5 (2014) 426431.

[30] J.L. Manzoori, G. Karim-Nezhad, Development of a cloud point extraction and preconcentration method for $\mathrm{Cd}$ and $\mathrm{Ni}$ prior to flame atomic absorption spectrometric determination, Anal. Chim. Acta, 2 (2004) 173-177.

[31] A.A. Gouda, A.M. Summan, A.H. Amin, Development of cloud-point extraction method for preconcentration of trace quantities of cobalt and nickel in water and food samples, RSC Adv., 96 (2016) 94048-94057.

[32] T.G. Kazi, H.I. Afridi, N. Kazi, M.K. Jamali, M.B. Arain. Copper, chromium, manganese, iron, nickel, and zinc levels in biological samples of diabetes mellitus patients, Biol. Trace Elem. Res., 1 (2008) 1-18.

[33] F.A. Lobo, D. Goveia, A.P. Oliveira, L.P.C. Romão, Development of a method to determine $\mathrm{Ni}$ and $\mathrm{Cd}$ in biodiesel by graphite furnace atomic absorption spectrometry, Fuels, 1 (2011) 142-146.

[34] P. Liang, L. Peng, "Determination of nickel in water samples by graphite furnace atomic absorption spectrometry after ionic liquidbased dispersive liquid-liquid microextraction preconcentration, Atom. Spec., 2 (2012) 53-58.

[35] Y Xu, J Zhou, G Wang, J Zhou, G Tao, Determination of trace amounts of lead, 
arsenic, nickel and cobalt in high-purity iron oxide pigment by inductively coupled plasma atomic emission spectrometry after iron matrix removal with extractant-contained resin, Anal. Chim. Acta, 1 (2007) 204-209.

[36] F. Zhou, C. Li, H. Zhu, Y. Li, A novel method for simultaneous determination of zinc, nickel, cobalt and copper based on UV-VIS spectrometry, Optik, 182 (2019) 58-64.

[37] X. Lu, L. Wang, K. Lei, J. Huang, Y. Zhai, Contamination assessment of copper, lead, inc, manganese and nickel in street dust of Baoji, NW China, J. Hazard. Mater., 3 (2009) 10581062.

[38] Q. Zhou, A. Xing, K. Zhao, Simultaneous determination of nickel, cobalt and mercury ions in water samples by solid phase extraction using multiwalled carbon nanotubes as adsorbent after chelating with sodium diethyldithiocarbamate prior to high performance liquid chromatography, J. Chromatogr. A, 1360 (2014) 76-81.

[39] Q. Han, Y. Huo, L. Yang, X. Yang, Y. He, J. $\mathrm{Wu}$, Determination of trace nickel in water samples by graphite furnace atomic absorption spectrometry after mixed micelle-mediated cloud point extraction, Molecules, 10 (2018) 2597.

[40] G. Férey, C. Mellot-Draznieks, C. Serre, F. Millange, J. Dutour, S. Surble, I. Margiolaki, A chromium terephthalate-based solid with unusually large pore volumes and surface area, Sci., 309 (2005) 2040-2042.

[41] M.S. Alivand, M. Shafiei-Alavijeh, Tehrani NHMH, E. Ghasemy, A. Rashidi, S. Fakhraie, Facile and high-yield synthesis of improved MIL-101(Cr) metal-organic framework with exceptional $\mathrm{CO} 2$ and $\mathrm{H}_{2} \mathrm{~S}$ uptake; the impact of excess ligand- cluster, Micropor. Mesopor. Mater., 279 (2019) 153-164.

[42] M. Montazerolghaema, S.F. Aghamiri, S. Tangestaninejad, M.R. Talaie, Metal-organic framework MIL-101 doped with metal nanoparticles ( $\mathrm{Ni} \& \mathrm{Cu}$ ) and its $\mathrm{e} \square$ ect on $\mathrm{CO} 2$ adsorption properties, RSC Adv., 6 (2016)
632-640.

[43] S. Pourebrahimi, M. Kazemeini, L. Vafajoo, Embedding graphene nanoplates into MIL101(Cr) pores: synthesis, characterization, and $\mathrm{CO} 2$ adsorption studies, Ind. Eng. Chem. Res., 56 (2017) 3895-3904.

[44] N.A.A. Qasem, N.U. Qadir, R. Ben-Mansour, S.A.M. Said, Synthesis, characteriza- tion, and $\mathrm{CO} 2$ breakthrough adsorption of a novel MWCNT/MIL-101(Cr) composite, J. CO2 Util. 22 (2017) 238-249.

[45] P.L. Llewellyn, S. Bourrelly, C. Serre, A. Vimont, M. Daturi, L. Hamon, G.D. Weireld,

J.S. Chang, D.Y. Hong, Y.K. Hwang, S.H. Jhung, G. Fe'rey, High uptakes of $\mathrm{CO} 2$ and $\mathrm{CH} 4$ in mesoporous metals organic frameworks MIL100 and MIL-101, Langmuir J., 24 (2008) $7245-7250$.

[46] S. Kayal, B. Sun, A. Chakraborty, Study of metal-organic framework MIL-101(Cr) for natural gas (methane) storage and compare with other MOFs (metal-organic frameworks), Energ., 91 (2015) 772-781.

[47] K. Munusamy, G. Sethia, D.V. Patil, P.B.S. Rallapalli, R.S. Somani, H.C. Bajaj, Sorption of carbon dioxide, methane, nitrogen and carbon monoxide on MIL- 101(Cr): volumetric measurements and dynamic adsorption studies, Chem. Eng. J., 195 (2012) 359-68.

[48] P. Chowdhury, S. Mekala, F. Dreisbach, S. Gumma, Adsorption of $\mathrm{CO}, \mathrm{CO} 2$ and $\mathrm{CH} 4$ on $\mathrm{Cu}-\mathrm{BTC}$ and MIL-101 metal organic frameworks: effect of open metal sites and adsorbate polarity, Mesopor. Mater., 152 (2012) 246-252.

[49] P.Á Szilágyi, P. Serra-Crespo, J. Gascon, H. Geerlings, B. Dam, The impact of postsynthetic linker functionalization of MOFs on methane storage: the role of defects, Front. Energ. Res., 4 (2016) 9.

[50] Z. Yu, J. Deschamps, L. Hamon, P.K. Prabhakaran, P. Pre, Hydrogen adsorption and kinetics in MIL-101(Cr) and hybrid activated carbon-MIL-101(Cr) materials, Int. J. Hydrogen Energ., 45 (2017) 8021-8031. 
[51] A. Malouche, G. Blanita, D. Lupu, J. Bourgon, J. Nelayah, C. Zlotea, Hydrogen absorption in $1 \mathrm{~nm}$ Pd clusters confined in MIL-101(Cr), J. Mater. Chem., 44 (2017) 23043-23052.

[52] N. Bimbo, W. Xu, J.E. Sharpe, V.P. Ting, T.J. Mays, High-pressure adsorptive sto- rage of hydrogen in MIL-101 (Cr) and AX-21 for mobile applications: Cryocharging and cryokinetics, Mater. Design., 89 (2016) 10861094.

[53] G. Blăniţă, M. Streza, M.D. Lazăr, D. Lupu, Kinetics of hydrogen adsorption in MIL- 101 single pellets, Int. J. Hydrogen Energ., 42 (2017) 3064-3077.

[54] X. Zhou, W. Huang, J. Miao, Q. Xia, Z. Zhang, H. Wang, Z. Li, Enhanced separation performance of a novel composite material GrO@MIL-101 for $\mathrm{CO} 2 / \mathrm{CH} 4$ binary mixture, Chem. Eng. J., 266 (2015) 339-344.

[55] M.S. Alivand, F. Farhadi, Multi-objective optimization of a multi-layer PTSA for LNG production, J. Nat. Gas Sci. Eng., 49 (2018) 435-446.

[56] Q. Yan, Y. Lin, C. Kong, L. Chen, Remarkable $\mathrm{CO} 2 / \mathrm{CH} 4$ selectivity and $\mathrm{CO} 2$ ad- sorption capacity exhibited by polyamine-decorated metal-organic framework ad- sorbents, Chem. Commun., 49 (2013) 6873-6875.

[57] Y. Lin, H. Lin, H. Wang, Y. Suo, B. Li, C. Kong, L. Chen, Enhanced selective CO2 adsorption on polyamine/MIL-101(Cr) composites, J. Mater. Chem. A., 2 (2014) 14658-14665.

[58] Z. Zhou, L. Mei, C. Ma, F. Xu, J. Xiao, Q. Xia, Z. Li, A novel bimetallic MIL-101(Cr, Mg) with high $\mathrm{CO} 2$ adsorption capacity and $\mathrm{CO} 2 /$ N2 selectivity, Chem. Eng. Sci., 147 (2016) 109-117.

[59] Q. Liu, L. Ning, S. Zheng, M. Tao, Y. Shi, Y. He, Adsorption of carbon dioxide by MIL-101(Cr): regeneration conditions and influence of flue gas contaminants, Sci. Rep., 3 (2013) 2916.

[60] Y. Wang, Y. Zhang, Z. Jiang, G. Jiang, Z. Zhao, Q. Wu, Y. Liu, Q. Xu, A. Duan, C. Xu, Controlled fabrication and enhanced visiblelight photocatalytic hydrogen pro- duction of Au@CdS/MIL-101 heterostructure, Appl. Catal. B: Environ., 185 (2016) 307-314.

[61] X. Li, Y. Pi, Q. Xia, Z. Li, J. Xiao, TiO2 encapsulated in Salicylaldehyde-NH2-MIL$101(\mathrm{Cr})$ for enhanced visible light-driven photodegradation of MB, Appl. Catal. B: Environ., 191 (2016) 192-201.

[62] M.L. Hu, V. Safarifard, E. Doustkhah, S. Rostamnia,A. Morsali, N. Nouruzi, S. Beheshti, K. Akhbari, Taking organic reactions over metal-organic frameworks as heterogeneous catalysis, Micropor. Mesopor. Mater., 256 (2018) 111-127.

[63] L. Qin, Z. Li, Z. Xu, X. Guo, G. Zhang, Organicacid-directed assembly of iron-carbon oxides nanoparticles on coordinatively unsaturated metal sites of MIL-101 for green photochemical oxidation, Appl. Catal. B: Environ., 179 (2015) 500-508.

[64] M. Shafiei, M.S. Alivand, A. Rashidi, A. Samimi, D. Mohebbi-Kalhori, Synthesis and adsorption performance of a modified micromesoporous MIL-101 (Cr) for VOCs removal at ambient conditions, Chem. Eng. J., 341 (2018) 164-174.

[65] P.B. Rallapalli, M.C. Raj, S. Senthilkumar, R.S. Somani, H.C. Bajaj, HFfree synthesis of MIL101 (Cr) and its hydrogen adsorption studies, Environ. Prog. Sustain. Energ., 2 (2016) 461-468.

[66] N. Tian, The synthesis of mesostructured NH 2-MIL-101 (Cr) and kinetic and thermodynamic study in tetracycline aqueous solutions, J. Porous Mater., 5 (2016) 1269-1278.

[67] M. Behbahani, V. Zarezade, A. Veisi, F. Omidi, S. Bagheri, Modification of magnetized MCM41 by pyridine groups for ultrasonic-assisted dispersive micro-solid-phase extraction of nickel ions, Int. J. Environ. Sci. Technol., 10 (2019) 6431-6440. 